\title{
A new vehicle for urban freight? An ex-ante evaluation of electric cargo bikes in courier services
}

\author{
Johannes Gruber * , Alexander Kihm, Barbara Lenz \\ German Aerospace Center (DLR), Institute of Transport Research, Rutherfordstrasse 2, 12489 Berlin, Germany
}

\section{A R T I C L E I N F O}

\section{Article history:}

Received 30 September 2013

Received in revised form 28 February 2014

Accepted 14 March 2014

Available online $\mathrm{xxxx}$

\section{Keywords:}

Courier service

Electric cargo bike

User acceptance

Binary logit model

\begin{abstract}
A B S T R A C T
One possible strategy to tackle the negative effects of urban freight is the substitution of cars by electric cargo bikes for inner-city courier shipments. This paper determines whether there is a potential market for electric cargo bikes, how the current market is organized, how electric cargo bikes are perceived by bike and car messengers, and what factors drive their willingness to use them. We find that in terms of cost, payload and range, electric cargo bikes lie in between two existing modes (bikes and cars) that have a largely overlapping market. Vehicle choice is commonly made by freelance messengers, as many courier companies don't operate their own fleets. Therefore they can contribute only indirectly to the dissemination of electric cargo bikes by considering them in their operational management. Despite the fact that most messengers have not used an electric cargo bike before, it was generally regarded to be suitable for courier shipments. Using a binary logit model, we find that messengers' demographics, their professional practice as well as their attitudes and values have significant impacts on their willingness to use electric cargo bikes. Critical factors for actual implementation appear to be electric range, purchase price and publically available information.
\end{abstract}

(C) 2014 Elsevier Ltd. All rights reserved.

\section{Introduction}

Technical innovations, particularly in vehicle design, will play a very considerable role in the future in reducing emissions, especially in urban areas. In combination with new concepts in the organization of mobility and transport, they can contribute significantly to greater sustainability in transport. Comprehensive overviews of efficient and sustainable strategies for last-mile deliveries have been given by Giuliano, O'Brien, Dablanc, and Holliday (2013) and Browne, Piotrowska, Woodburn, and Allen (2007). One of these strategies is the use of electric vehicles for urban freight (van Duin, Tavasszy, \& Quak, 2013). As the market for currently available electric cars, and especially larger electric vehicles, is still limited, some focus is being placed on introducing smaller electric vehicles such as electric cargo bikes (E-CBs). The use of these vehicles is currently being discussed as one interesting possibility of configuring urban transport more sustainably (Lenz \& Riehle, 2012). E-CBs are seen as having particular potential here, as they enable both greater loads and larger distances than is possible with the purely human-powered cargo bikes, tackling common disadvantages of cycle freight such as range, payload and driver fatigue (Transport for London, 2009). For this reason, there is currently a whole series of projects in Europe testing whether or in what way (electric) cargo bikes can be used in a way that makes economic and ecological sense. Two fleet

\footnotetext{
* Corresponding author. Tel.: + 493067055 200; fax: +49 3067055283 .

E-mail address: johannes.gruber@dlr.de (J. Gruber).
}

trials of cargo tricycles, both in combination with an urban microconsolidation center, have proven successful in Paris (Dablanc, 2011) and London (Leonardi, Browne, \& Allen, 2012).

Positive expectations are not universally shared, however. Analyzing the US situation, Giuliano et al. (2013) come to the conclusion that the use of alternative fuels and vehicles for inner-city deliveries is an urban freight strategy with only "low effectiveness" and therefore also only "medium applicability to [the] United States". The differing estimation of the potential of cargo bikes in inner-city courier services doubtless reflects the massive difference between US and European inner-city structures (Le Galès \& Zagrodzki, 2006), where E-CB-suitable transport demand might only be similar in limited metropolitan core areas (Conway, Fatisson, Eickemeyer, Cheng, \& Peters, 2011).

In all, however, there is hardly any knowledge regarding the potential and conditions of E-CB use in city-center commercial transport today. The European experience shows that a multitude of different conditions are to be taken into account when estimating the potential of cargo bikes. Among these, alongside the technical and infrastructural prerequisites, are the corporate structures on the supply side, the spatial and temporal demand patterns, and also the acceptance of the new transport mode on the part of companies and their drivers and riders. The latter also applies to drivers who currently use regular bicycles or cars for courier services, and thus belong to the group of potential E-CB users.

These various factors and the interactions between them will be described and discussed more closely in the following using the example of urban courier services. Courier services are seen as an appropriate 
sector for an in-depth ex-ante evaluation, as they are the most reliable, flexible and expensive segment of CEP (courier, express, parcel) services, operating with small-scale shipments in densely populated urban centers (Glaser, 2000; Maes \& Vaneslander, 2012; Witte, Krichel, \& Sommer, 2011). The E-CB reference model used - a competitor to the existing markets of bike and car shipments - is a 2-wheel vehicle as pictured in Fig. 1. This type of construction (so called "Long John"), with a cargo box between front wheels and handlebars, is generally favored by messengers for point-to-point shipments compared to tricycles (Riehle, 2012).

The basis for this research is the empirical study of courier companies and individual messengers, with the aim of establishing and gauging the prerequisites and possibilities for integrating E-CBs in available corporate structures and transport services provision, and understanding the role of possible decision-makers concerning vehicle choice.

The article is structured as follows: following this introduction, we describe the data that we have gathered in answering the research question, and the methods we have used in evaluating these data (chapter 2). Chapter 3 contains the initial approximation for determining the potential of E-CBs. To this end, we analyze on the one hand trip patterns which we illustrate using the example of Berlin, and on the other hand the characteristics of the shipments made by the companies studied. In Chapter 4, we consider the current organization of courier services in inner cities; vehicle costs and company organization are at the forefront here. The fifth main chapter looks at the professional background of current bike and car messengers, their awareness of and acceptance of E-CBs, as these are the people who would actually use them. In the process, we observe the influence of socio-demographic factors, current service practices, attitudes and values on the acceptance of cargo bikes. Acceptance is here defined as "willingness to use". In order to determine the strength of the influencing factors, we have used binary logit models whose results we describe in chapter 6 . The article closes with remarks on the implications of this research.

\section{Research questions, data and methods}

This research is guided by the central question of whether there is a potential market for E-CBs (electric cargo bikes) in urban courier services. To answer this question, it is necessary on the one hand to understand the specific structure of shipments that are carried out by bike or by car; on the other we need to consider the acceptance of E-CBs by the bike and car messengers who would use this new mode. To this end, we have investigated how E-CBs are perceived by potential users (i.e. bike and car messengers), and what motives support or impede messengers' willingness to adopt this mode of transport. Against this background, we have used an approach that relies on a series of various empirical data that we analyzed with descriptive statistical methods and a binary logit model.

Eight German courier companies provided quantitative data for research. All of them are among the three biggest market players in their home cities which are (in rank of size) Berlin, Hamburg, Munich, Düsseldorf, Leipzig, Bremen, Nuremberg and Mainz. The database provided (dataset 1) contains all trip data for one year of business (May 2011 to April 2012) for all modes of transportation, except for 2 companies who applied a regional filter (metropolitan area) before transferring the data (therefore Fig. 2 shows 6 business areas only). 752,334 single shipment distances (3\% of the German courier services market, see MRU GmbH, 2012) were used for mapping the companies' spatial extension. A core business area was defined as at least 1 pickup or 1 drop-off per week per zip code.

For an in-depth analysis of courier shipments, one company based in Berlin was selected. The sample for this research was filtered by mode of transport and shipment type. Regarding mode of transport, as an E-CB would be positioned between the markets of regular bicycle shipments and (passenger) car shipments, only these two modes were taken into consideration. Shipments by small utility vehicles (vans) or other vehicles were not considered. In terms of shipment type, like most of the courier companies, two main types of services are offered: point-topoint shipments and overnight deliveries to any national or international destination, where the first and last mile is bridged by messengers. Only point-to-point shipments were considered (84\% of all bike shipments and $86 \%$ of all car shipments), as overnight trip data records didn't allow a retracing of the messengers' route. Information concerning type, volume or weight of the transported good was partly manually coded into a new variable assessing whether the specific goods are feasible for transport in a typical cargo box on top of a 2-wheel E-CB with a load rate of up to $100 \mathrm{~kg}$ (with no parcel more than $25 \mathrm{~kg}$ ) and a cargo box with a volume of $78 \mathrm{~cm} \times 48 \mathrm{~cm} \times 47 \mathrm{~cm}(176 \mathrm{l})$ as pictured in Fig. 1. The final shipment-related data sample contained 59,501 car shipments and 88,391 bike shipments (dataset 2).

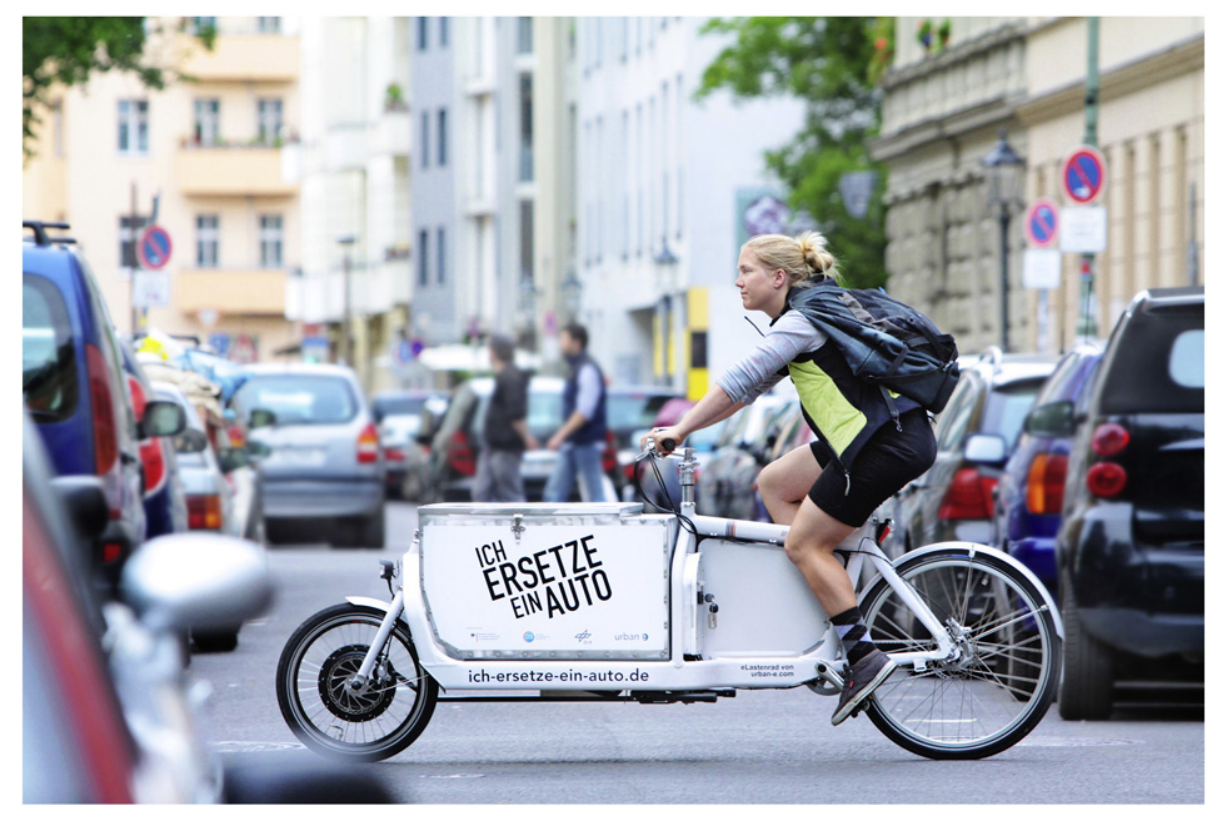

Fig. 1. Example picture of a 2-wheel electric cargo bike (E-CB) as used in the project "Ich ersetze ein Auto" by German courier companies. Photo credit: Amac Garbe for DLR. 

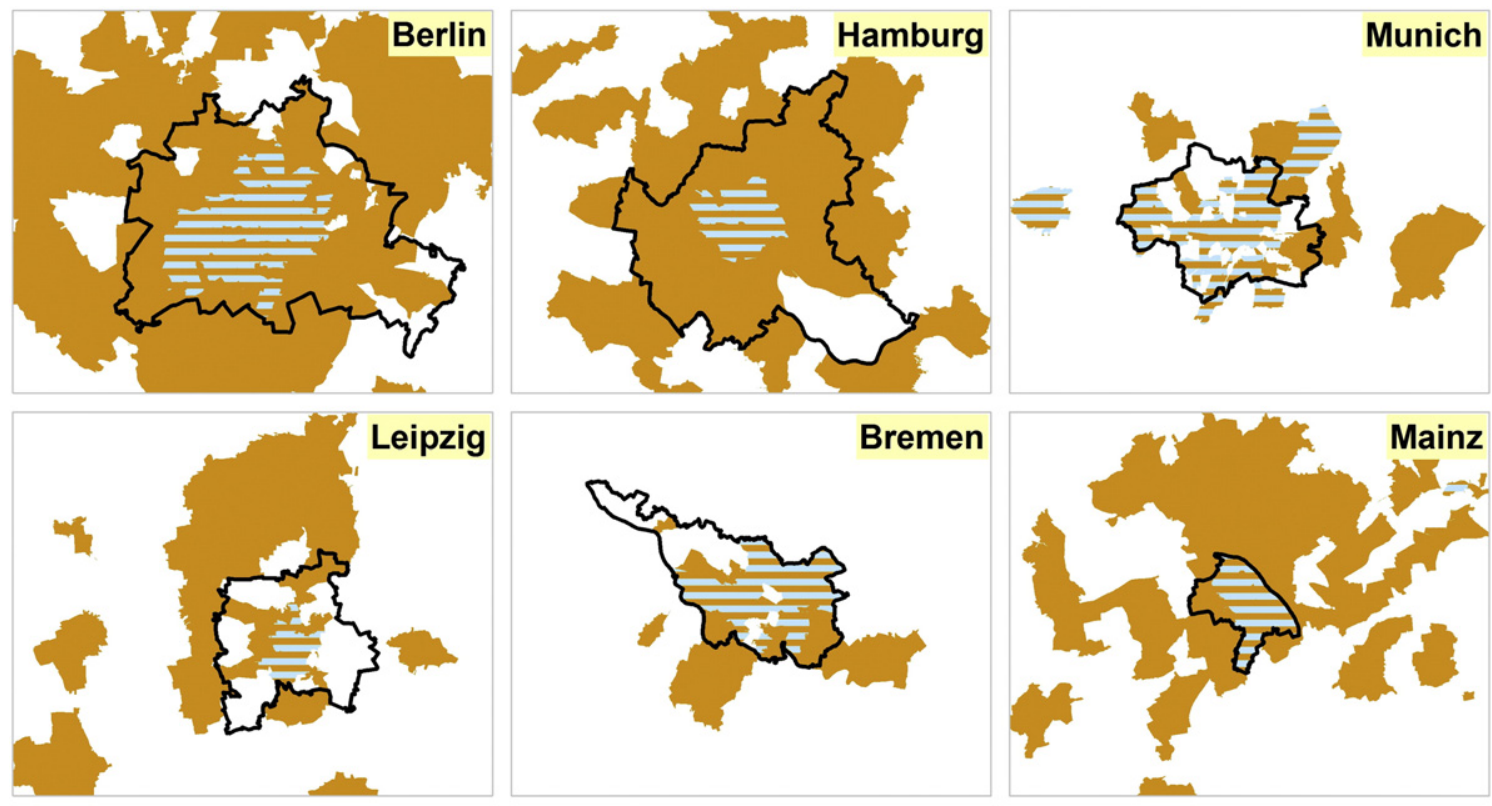

Bike shipments

Car shipments

City boundaries

$10 \mathrm{~km}$

Fig. 2. Core business areas of 6 German courier companies in six major German cities.

In order to aggregate daily mileages from the trip data records, shipments were aggregated to trip chains in a multistep process. Trips had to contain information about origin and destination (OD) addresses (which was geocoded by Nokia Maps) as well as the time stamps of pickup and drop-off. Selected trips were bundled by individual messenger ID and date. Each bundle was then sorted chronologically to retrace the messengers' trip chain, resulting in ordered relations between pickup and drop-off locations. These OD-relations were routed using two road networks of Berlin (one for cars and one for bicycles), generated with OpenStreetMap (OSM) data as of July 2013. Finally, 28,312 single shipments (19\%) were able to be transformed into trip chains, forming 2383 daily trip chains by 69 bike messengers and 2607 daily trip chains by 54 car messengers (dataset 3 ).

In order to gain qualitative understanding of the current organization of courier services, their employment and remuneration structure as well as type, cost and financing of used vehicles, CEOs, dispatchers and messenger supervisors of the eight German courier companies were interviewed in expert and group discussions.

To analyze the messengers' willingness to use an E-CB as a means of transport for their daily courier job, we conducted a survey among all 590 messengers of the eight companies involved in our research project. Between June and October 2012, 191 of them returned our questionnaire sufficiently filled out for detailed modeling, yielding a good return rate of $32 \%$, roughly $8 \%$ of the German messenger workforce. For further analysis the sample (dataset 4 ) was divided into 92 car messengers (stating any combustion engine vehicle as their favorite mode of transport for courier services) and 99 bike messengers (stating bicycles or cargo bikes as favorite mode of transport).

We tested respondents' willingness to use E-CBs in a practical way by asking them if they would like to try one out in their job for three months. To reduce potential bias stemming from hastily considered acceptance or disapproval because of financial ramifications, we did not offer the tryout for free, nor did we charge the full cost; instead, we offered the participation for $€ 35$ per month as a compromise between necessary outlay and sufficient attraction.

The survey requested information about the respondents' sociodemographics, attitudes, courier practice and job satisfaction, as well as their assessment of E-CB technology and its potential impact.
To measure these variables' influence on the binary-dependent willingness-to-use variable described above, we employed a binary discrete choice model. This model has been successfully used up to the present day for many acceptance and adoption studies, in areas as diverse as energy (Liu, Wang, \& Mol, 2013), agriculture (Mariano, Villano, \& Fleming, 2012), land use (Jongeneel, Polman, \& Slangen, 2008) and especially transport (Holguín-Veras \& Wang, 2011; Ye, Mokhtarian, \& Circella, 2012) and technology forecasting (Cheng \& Yeh, 2011). Since we have applied the model in a classic and unmodified form, the reader is referred to Ben-Akiva and Lerman (1985) for details on the mathematical foundations.

\section{The potential market for $\mathrm{E}-\mathrm{CB}$}

To answer the question of whether a new type of vehicle can be successful in the urban courier logistics market, it is essential to know the structures that are shaped by the demand for bike and car shipments today. This chapter presents the results of a data analysis of courier company trip records. First, the places of demand for bike and car shipments are visualized for 6 German cities, followed by a close-up perspective of central Berlin. Trip-related features such as shipment distance, weight/ volume and time are examined for bike and car shipments. Finally, collapsing single trips into daily trip chains gives valuable insights about the necessary electric ranges.

\subsection{Distribution of bike and car shipments in urban areas}

The possibility of applying E-CBs to courier services depends on the existing structure of shipments and the presently used modes of transport, namely bicycles and cars. The analyzed structure of courier services in German cities is concentrated in densely populated core areas. Fig. 2 maps areas where the courier companies are active at least occasionally, both for shipments by car and by bike (using dataset 1 ). Also displayed are the city perimeters, covering urban areas between $892 \mathrm{~km}^{2}$ (Berlin) and $98 \mathrm{~km}^{2}$ (Mainz).

The area covered by bike messengers ranges from $48 \mathrm{~km}^{2}$ (Leipzig) to $382 \mathrm{~km}^{2}$ (Munich) with a mean of $170 \mathrm{~km}^{2}$. In Munich, the wider spread of bicycle deliveries is due to messengers using public 
transportation with their bike for long distances or living in towns neighboring the metropolitan area. Car messengers are active both in the city center and city outskirts or surrounding neighborhoods. But as the maps in Fig. 2 show in unison, car messengers cover the whole business areas of bike messengers, resulting in a large market overlap. The areas regularly covered by car messengers range from $320 \mathrm{~km}^{2}$ (Bremen) to $3459 \mathrm{~km}^{2}$ (Berlin) and have a mean of $1466 \mathrm{~km}^{2}$.

Despite the wider areal spread of car shipments, both bike (99\%) and car $(82 \%)$ trips are mostly carried out inside the city perimeter. On a more detailed level, demand for courier shipments is highly concentrated in specific inner-city areas, as the following in-depth analysis of Berlin (using dataset 2) shows.

\subsection{A case study: Berlin}

Berlin is the largest city in Germany by size (3.3 million inhabitants) and area $\left(892 \mathrm{~km}^{2}\right)$. Population density varies significantly within the city. In the inner-city area - a low emission zone, surrounded by a circular railway - one million people live on $88 \mathrm{~km}^{2}$ (112 inhabitants per hectare). On the other hand, some of the outskirts contain large areas of forest or water surfaces and are far less densely populated (28 inhabitants per hectare). A high share of economic activity and traffic is accordingly located within the inner-city area. There are 77,100 places of business ( 9 sites per hectare), which comprises $46 \%$ of all places of business in Berlin (Infas geodaten $\mathrm{GmbH}, 2011$ ).

Fig. 3 shows the spatial patterns of observed shipments by mode for the inner city of Berlin. $83 \%$ of the pickup locations (origins) and $77 \%$ of the drop-off locations (destinations) are positioned within the inner city perimeter. Linking origins and destinations, we found out that two thirds of the shipment relations are inside the inner city.

Distinguishing by mode, bike shipments are more concentrated than car shipments: $85 \%$ of the bike shipments have origin and destination within the inner city, $11 \%$ link areas inside the inner city with other parts of Berlin and $4 \%$ of the relations lie completely outside the inner city. Car shipments, on the other hand, consist of 39\% inner city relations, $34 \%$ inside-outside relations and $28 \%$ tangential relations outside the city center.

Still, in large parts of the most important inner city business areas, the markets for the two modes overlap to a high degree. Inner-city demand is concentrated in the "Mitte" borough where many public facilities and business-related services are located. Demand stretches mainly from the former center of East Berlin to the so-called City-West in the neighboring borough of Charlottenburg. Being a polycentric city, however, there are several other attraction points with high densities of offices, retail and healthcare services. Consequently, almost the whole inner-city area shows an interwoven network of OD-relations. In contrast, a high degree of demand outside the city center arises from singular locations, i.e. warehouses of key account costumers.

\subsection{Key features of courier shipments: distance, weight/volume, time}

Besides this spatial expansion of courier services, we investigated further differences between the two modes and the resulting consequences for potential E-CB use: shipment distance, goods weight/ volume and the temporal attributes of courier services demand.

Contrary to express or parcel deliveries, the courier market is characterized by a high share of short-distance trips. Mean distance for bike shipments in Berlin is $5.1 \mathrm{~km}$, against $11.3 \mathrm{~km}$ for car shipments. Fig. 4 shows the distribution of distances up to $40 \mathrm{~km}$ (99.5\% of the sample) for bike and car shipments. Both distributions are positively skewed, i.e. having many cases between $0 \mathrm{~km}$ and a certain upper threshold, followed by a decreasing amount of shipments at a variety of longer distances. $92 \%$ of the assignments carried out by bikes and $56 \%$ of those carried out by cars have $10 \mathrm{~km}$ or less shipment distance; $99 \%$ of the bike shipments and $87 \%$ of the car shipments are shorter than $20 \mathrm{~km}$. It seems reasonable that messengers on an electrically-assisted vehicle such as an E-CB would also accept shipment distances of up to $10 \mathrm{~km}$ or $20 \mathrm{~km}$.

Besides shipment distance, the goods' weight and volume might also determine the competitiveness of different modes in courier services. If weight and volume were the only limiting factors, all bike shipments and $85 \%$ of the car shipments could be carried by E-CBs with a cargo box of 176 1, as shown in Fig. 1.

Assuming a maximum shipment distance threshold at $10 \mathrm{~km}$, and only taking into account goods that fit by weight and volume into the cargo box, the technical potential of E-CBs can be derived: $42 \%$ of the car shipments would be substitutable by E-CBs. This share accounts for $19 \%$ of the mileage that is today generated by cars. A threshold of $20 \mathrm{~km}$ maximum shipment distance would extend this potential to $68 \%$ of all car shipments and $48 \%$ of the resulting mileage.

Courier shipments might underlie specific temporal constraints as companies allow their clients to specify a precise delivery window. $12 \%$ of the bike shipments and $18 \%$ of the car shipments are labeled as time-sensitive in this sense. Motorized modes of transport might therefore be seen as more trustworthy when it comes to meeting precise delivery windows. Interestingly, the mean cruising speeds of the two modes differ only slightly: $17.3 \mathrm{kph}$ for car shipments and $15.9 \mathrm{kph}$ for bike shipments. As pedal electric vehicles (Pedelecs) are allowed to be electrically assisted up to $25 \mathrm{kph}$, it seems possible that a similar

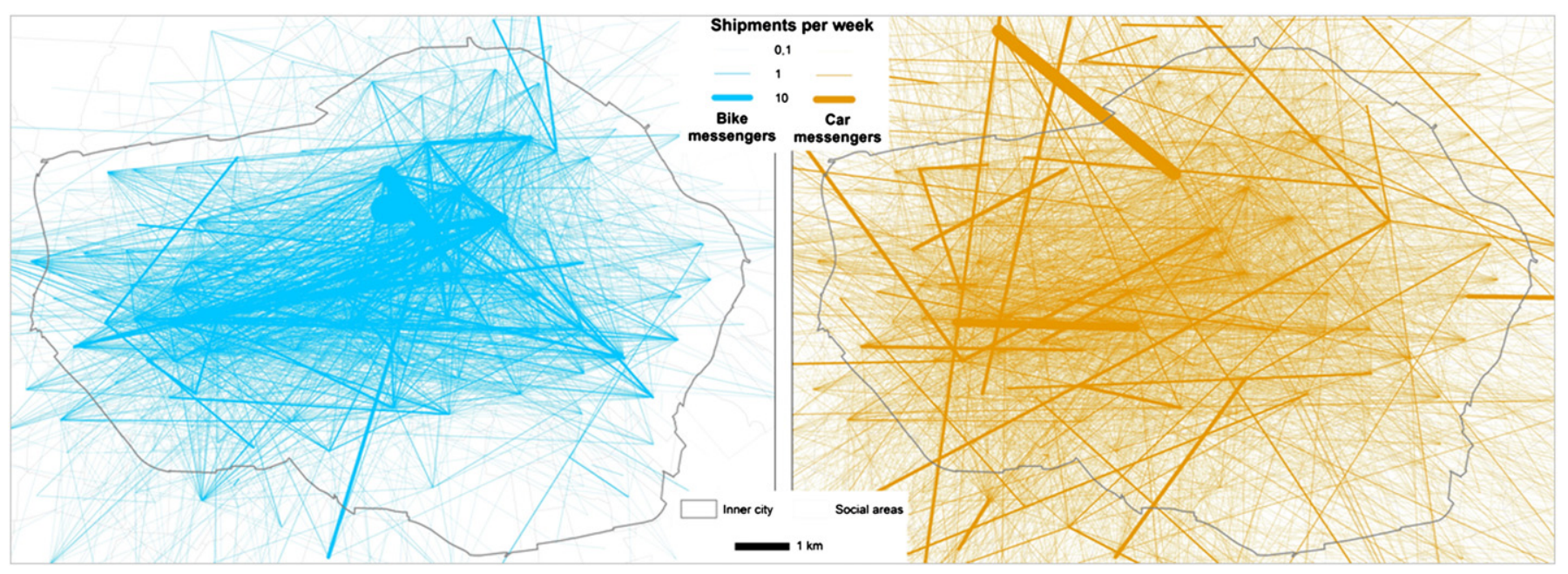

Fig. 3. OD-relations of courier shipments by bikes and cars in central Berlin. 

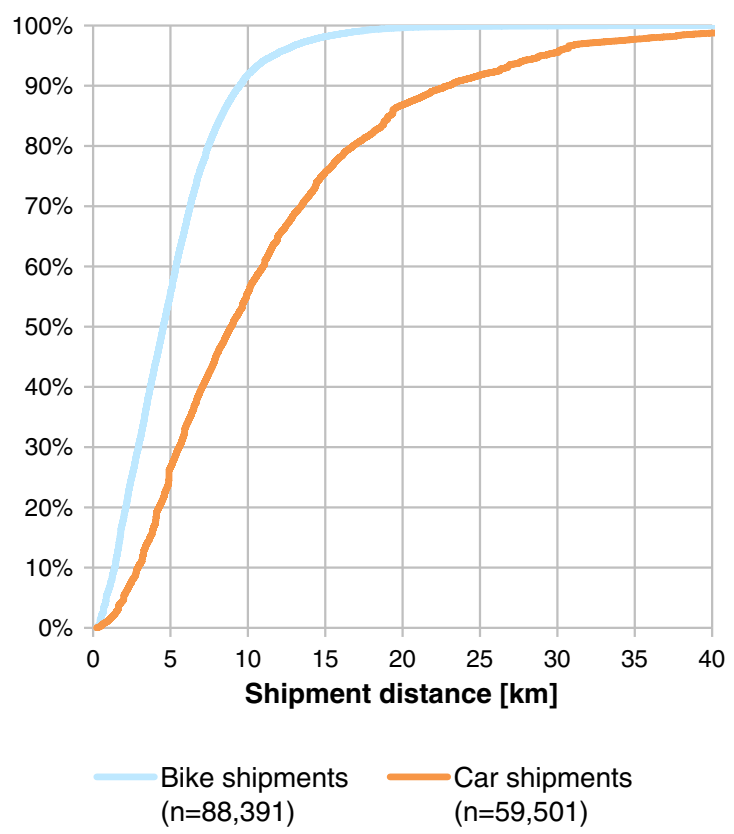

Fig. 4. Bike vs. car shipments: cumulative frequencies of single shipment distances.

cruising speed can be achieved by E-CBs to meet the markets' temporal constraints.

One obvious difference between car and bike is the exposure to weather. However, we found no substantial fluctuations concerning the amount of car and bike shipments and especially their difference throughout the year. Similarly, demand for bike and car shipments runs very much in parallel throughout the day. For users of the innercity road network, traffic hours may be relevant in selecting the best mode of transport. However, during the most congested times (weekday rush hours from 6 to 9 a.m. and 4 to 6 p.m.) when cars might be disadvantaged due to many commuters, only one sixth of bike and car shipments takes place. The main business hours for bike (82\%) and car (79\%) messengers are regular office hours and the time after the evening rush-hour, when the road network has a medium usage (weekdays 9 a.m-4 p.m. and 6-8 p.m). Weekend deliveries are negligible for practical purposes.

\subsection{Duration and daily mileages of courier trip chains}

As seen above, bike messengers deliver goods over a shorter distance than car messengers which allows them to manage more shipments per day. Using dataset 2 (single trips), the mean number of shipments per day by bike messengers is 9.4 and 6.4 by car messengers, respectively. In the following results from dataset 3 (aggregated trip chains) will be used. Here we observed smaller means: 6.4 daily shipments for bike messengers and 5.0 for car messengers, respectively. This is due to the exclusion of trip chains without complete information on all trip attributes when aggregating from dataset 2 to dataset 3 .

Independent of that the quantity of daily assignments in courier services is much smaller than usual figures in the parcel segment, where delivery tours can contain up to 200 parcels (Schumacher, 2012). This is due to the types of flows (point-to-point shipments vs. round trips) and the employment structure. While parcel delivery companies often operate with full-time employed drivers, a broad range of working times is common in the freelance-dominated courier market: one quarter of the bike (car) messengers work less than 2.9 (2.6) hours per day, while another quarter of the bike (car) messengers work more than 7.0 (7.3) hours per day. The mean aggregated time for daily trip chains is $5.3 \mathrm{~h}$ for both modes. These values exclude the additional ways from home to the first pickup and homewards after the last delivery. There is a large variety in daily mileages, too. We observed a range of 1-166 $\mathrm{km}$ for bike trip chains (mean: $42 \mathrm{~km}$ ) and a range of 1-253 km for car trip chains (mean: $66 \mathrm{~km}$ ). $90 \%$ of the daily distances that performed by bicycles lie between 0 and $75 \mathrm{~km}$ in an almost uniform distribution (see Fig. 5).

It is important to consider daily mileages as this allows an assessment of which electric range would be best-suited for E-CBs in courier services. While the achievable electric range of E-CBs varies by many factors such as battery size, number of stops, degree of acceleration, physical support by the messenger, topography and payload, typical values currently aimed at by manufacturers are between 50 and 100 km. Fig. 5 shows that $62 \%$ (99\%) of the bike trip chains and $42 \%$ (78\%) of the car trip chains are below $50 \mathrm{~km}(100 \mathrm{~km})$ and would therefore be manageable by E-CB.

Even though the analyzed deliveries are "point-to-point shipments", only $57 \%$ of the total mileage is generated by transporting exactly one shipment from origin to destination. The rest of the mileage is generated by idle trips, i.e. a bridging distance without transporting any shipment (21\%) or combining several assignments by transporting 2 or more shipments at the same time ( $22 \%$ of total mileage). Surprisingly, these numbers don't vary by mode: car messengers do not transport a higher number of shipments simultaneously than bike messengers. Hence the amount of payload seems to be of minor importance for the bundling of shipments.

\section{Courier logistics organization today}

After the analysis of the market structure for urban courier services, this chapter offers a brief look into the operational management of how regional companies perform these services. To assess the potential of E-CBs for urban freight, we consider their cost and competing modes. Furthermore, the employment structure, pricing of courier services and dispatching of shipments to certain messengers need attention, as these processes might have an influence on the viability of E-CB implementation.

\subsection{Vehicle cost}

As seen above, E-CBs are most likely to penetrate a market located between bike and car shipments. In inner-city areas there is a fluent
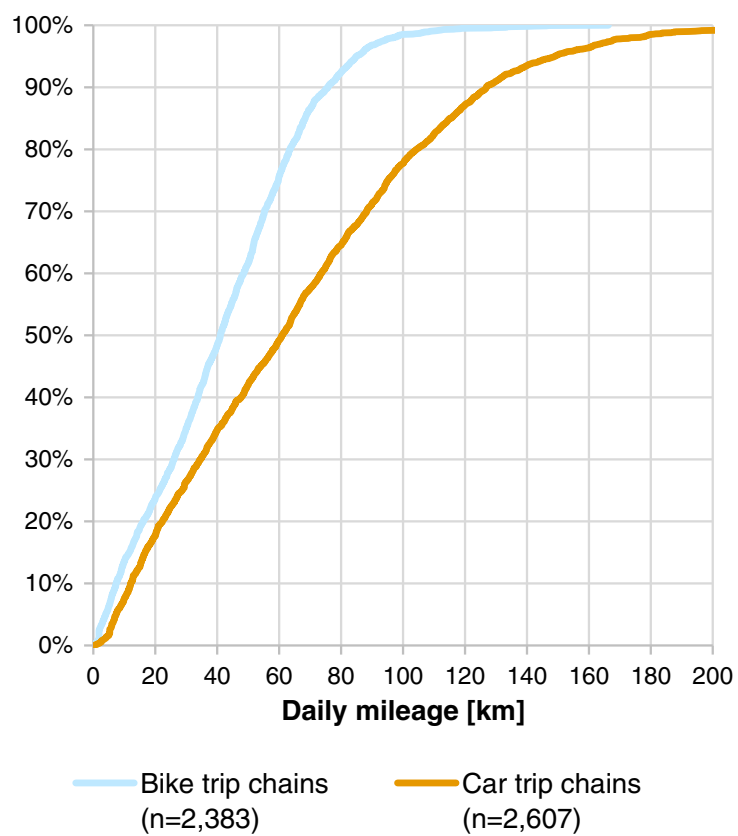

Fig. 5. Bike vs. car shipments: cumulative frequencies of aggregated daily mileages. 
transition between these two vehicles' markets, which overlap to a large extent. For logistics service providers, the cost of vehicles obviously is an important factor. Full-time bike and car messengers were therefore asked about the typical cost and form of acquisition, and the expenses for maintenance and fuel of their vehicles. This was contrasted with a finance model for a currently available 2 -wheel E-CB. Table 1 compares the three modes and allows a rough evaluation of the vehicle-triggered operating costs for vehicle owners.

While the cost of using bicycles and E-CBs for messenger shipments is naturally negligible concerning fuel costs, for car owners this is a significant part of their calculation. Following Table 1, an annual mileage of $10,000 \mathrm{~km}$ would add up to operating costs of $€ 1480$ for bicycles, $€ 3915$ for E-CBs, and $€ 7050$ for cars. Both cars and E-CBs have to deliver more goods or over longer distances in order to reach a break-even point. The income opportunities are mostly triggered by the number of shipments and shipment distance, as we will show in the following chapter.

\subsection{Courier companies' operational management}

While the courier segment accounts for $10 \%$ of all German CEP shipments (total: 2.5 billion shipments annually), its share in turnover is substantially higher, namely $22 \%$ of the total CEP turnover (€17.8 billion, MRU GmbH, 2012). How is this business organized? Besides nationwide operators, there is a high quantity of regionally operating courier companies. It is important to understand their everyday business in order to identify possible drivers and barriers for the establishment of a new vehicle. The key features of this industry can be summarized as follows:

- Company size and background: most regionally operating courier companies are micro entities (less than 10 employees) or small companies with 10-50 employees. The associated number of messengers, however, can be multiple times the number of employees. In this business, it is quite usual that members of middle and upper management or dispatchers have started as messengers themselves. All eight companies were founded in the beginning of the 1990s and suffered a significant downturn with the upcoming digitalization in the 2000s. Today, new markets are expanding, i.e. in healthcare and valueadded logistics.

- Employment: the CEP market is an employment-intense industry. Different estimations about the total number of employed/freelance persons within Germany lie between 188,000 (BIEK (Bundesverband Internationaler Express-und Kurierdienste) e.V., 2013) and 254,000 (MRU GmbH, 2012). The employment structure is complex and depends on subcontractors. Estimates for the couriers within CEP services put the number of car messengers in Germany at about 19,000 and the number of bike messengers at about 4500-5000. The majority of messengers of the eight analyzed courier companies work as freelancers.

- Remuneration: in the most self-organized form, messengers generate their earnings solely by trip revenue, while the courier company keeps a fee of between $25 \%$ and $40 \%$. The company serves as a broker and deals with all customer affairs. The fee share might vary by mode (some companies offer their car messengers a fuel surplus), by experience, monthly revenue, willingness to do off-hour shifts, etc. Some

Table 1

Common costs for purchase, maintenance and fuel for vehicles used in courier services.

\begin{tabular}{lllll}
\hline & Reference & Bike & E-CB & Car \\
\hline Purchase costs & One-time & $€ 1000$ & $€ 0$ & $€ 0$ \\
Leasing (down payment) & One-time & $€ 0$ & $€ 1500$ & $€ 0$ \\
Leasing (fee) & Monthly & $€ 0$ & $€ 100$ & $€ 300$ \\
Insurance & Monthly & $€ 0$ & $€ 10$ & $€ 80$ \\
Maintenance & Monthly & $€ 10$ & $€ 50$ & $€ 80$ \\
Spare parts & Monthly & $€ 30$ & $€ 40$ & $€ 40$ \\
Fuel & Per 100 km & $€ 0$ & $€ 0.15$ & $€ 10.50$
\end{tabular}

companies have mixed models with basic income plus provisionbased payment.

- Assets: vehicles are largely owned by individual messengers. Only one company owns a car fleet, while some companies have a small number of light commercial trucks which are rented out to messengers for specific tours.

- Pricing: most commonly the price for a courier service depends on the mode desired by the customer, which determines the size of a base fee (often including 1-2 km) and variable cost by extra km. Surpluses apply for specified delivery windows, waiting time, off-hour-pickups, unusual goods, etc. One company uses fixed cost by zip code relation and mode. We found a certain degree of smooth transition between the priced mode and the actual one, as messengers are allowed to accept deliveries regardless of the mode desired by the customer. In Berlin, $26 \%$ of the shipments with bicycle-pricing were actually transported by car. Vice versa, $14 \%$ of the car-priced shipments were done by bike messengers.

- Customers: almost all demand is B2B, as courier service is too pricy for most B2C needs. In Berlin, clients from five sectors account for $84 \%$ of the shipments of the company studied: media/arts (31\%), general services (18\%), health (12\%), business-oriented services (12\%) and banking/insurance (11\%). Partly, there is a high dependency on key accounts, which, reciprocally, often rely heavily on the courier companies' expertise, as the businesses have grown together.

- Order acceptance: orders are almost exclusively made by phone. While taking the order, either the customer desires a certain vehicle type or the call center agents makes a suggestion based on information about the type of shipment. However, in certain cases there is no knowledge on the type of good.

- Dispatching of shipments: a common form is an "open radio", where dispatchers call out the new shipment (i.e. by zip code relation) and messengers agree to the orders in a first-come first-serve principle (pullallocation). Other orders are distributed directly (push-allocation). Sometimes whole areas are designated to certain messengers. Larger companies use several radios for different modes or IT solutions.

Generally, we discovered a market where structures evolve gradually and sometimes lack strategic management. Some companies started only with bike shipments and had to implement larger vehicles, especially as the importance of documents and media transports decreased drastically and goods became heavier. E-CBs can be a possibility to lower fuel and maintenance cost and still be able to transport heavier goods. This would allow better pricing structures and an advantage against competitors.

Acting innovatively is often seen as part of the urban self-image of courier companies. Hence they seem willing to implement new technology or adapt to customer demand. In order to achieve this, a new type of vehicle like an $\mathrm{E}-\mathrm{CB}$ must be taken into account during the whole operational process. Existing customers might need specific information on this mode of transportation or new, eco-friendly customer groups could be targeted. Call center agents and dispatchers need briefing about the capabilities of the vehicle (e.g. payload). Parking spaces and charging infrastructure should be provided.

In the end, however, as long as courier companies do not operate with their own fleets, they can only pave the way for messengers' choice of using E-CBs or other modes of transport.

\section{E-CB acceptance: the messengers' perspective}

Individual messengers can be seen as a good proxy for the general acceptance of the courier market towards E-CBs. In fact, they have the highest influence in the type of vehicle used, as they use their own vehicles most of the time. Hence we find it important to understand this potential user group, its attitudes towards E-CBs and what drives them to actually implement these vehicles in their job. 


\subsection{Socio-demographics of surveyed messengers}

While the job of messenger is clearly favored by men (93\%), the business shows no dominating age group. $88 \%$ of the respondents are between 23 and 55 years old. Over this main age range we found an almost uniform distribution. Outside of it, the small tails span to 18 and 80 years.

The sample analyzed (dataset 4) contains both veterans and beginners of the business: $35 \%$ have been working as a messenger for more than 10 years, $13 \%$ started less than a year ago. Along the heterogeneous age distribution there is also heterogeneity of career paths previous to the recent job as messenger. About one third of the sample, mostly bike messengers, entered straight after university, high school or their apprenticeship, another third worked in a qualified profession in another branch of industry. Some changed from unskilled labor or unemployment into the courier business, while only $10 \%$ had already been working as messengers before.

About half of the respondents earn net wages between $€ 1001$ and $€ 2000$. Thirty-seven percent achieve a lower income (up to $€ 1000$ net wage), and $11 \%$ reported net wages above $€ 2000$. The respondents have a higher educational level than the German population average (Destatis, 2013) and the degree of high school graduates (64\%) is more than twice the share of all Germans 15 years and older. Since all respondents work for the 8 participating urban courier companies, they all live in large cities with more than 200,000 inhabitants.

When differentiating between bike messengers and car messengers, we find two very distinctive groups. Bike messengers are younger than car messengers (mean age $=35.3$ vs. 48.2 years), less male-dominated ( $90 \%$ vs. $96 \%$ ) and more highly educated ( $81 \%$ graduated at least from high school vs. $50 \%$ ). However, only $4 \%$ of the bike messengers achieve a net income of $2001 €$ and more (vs. 23\% of the car messengers). This might be associated with the higher degree of part-time workers and the more usual habit of having another profit-oriented activity besides the messenger job.

\subsection{Current vehicles and professional practices}

Due to the high dependence on their transportation means and their high presence in densely populated urban areas, messengers can be seen as pioneers of commercial vehicle use. Accordingly, 91\% of the respondents stated that they are interested in vehicle technology. In order to assess their perception of E-CBs, it is important to understand what types of vehicles they are currently using for courier services. Professional practices and routines might influence the will to adopt a new mode of transport.

Respondents were asked about their preferred mode of transport on duty, where $52 \%$ stated a vehicle without combustion engine ( $46 \%$ bicycle and $6 \%$ regular cargo bike). This group is referred to as bike messengers in this research. Forty-eight percent of the respondents stated a combustion engine vehicle as their favored mode of transportation (30\% mid-sized car/light commercial vehicle, 9\% small-sized car and 9\% SUV/transporter). These respondents were grouped as car messengers. The engines of car messengers are mostly powered by diesel (64\%), followed by gasoline (25\%) and CNG/LPG (10\%). The mean age of their vehicles is 6 years.

It does not seem unusual for bike messengers to occasionally use a car for some transport tasks: $14 \%$ have used a car during the last year at least once. Regarding E-CBs, despite the fairly high rate (9\%) of messengers that have already tested one for their work during the last year, only 2 respondents (1\%) own it. Regular cargo bikes are used by $21 \%$ and owned by $7 \%$ of the respondents.

The most common ownership (91\%) is to use self-owned vehicles; while all bike messengers own their vehicle, $12 \%$ of the car messengers use vehicles that they don't personally own (company fleet).

Over one third of the messengers visit their courier company's site several times a day. This fact could indicate that the necessary recharging periods for $\mathrm{E}-\mathrm{CB}$, i.e. during the night, are easily adaptable to everyday routines. Currently only a minority of $6 \%$ also park their vehicle at the establishment site after duty, the rest choose parking spaces close to home in private or public parking spaces.

For most messengers, almost equally for bike and car messengers, it is possible to combine several shipments, either by pull- or push-assignment.

\subsection{Messengers' awareness of and attitudes towards E-CBS}

In our survey, messengers of both types were confronted with statements about E-CBs in order to assess the awareness of this mode of transport and the possible users' attitudes towards it. Fig. 6 shows the statements of bike and car messengers.

Generally, messengers see a high potential for E-CBs in their actual urban surroundings. About $60 \%$ of both bike and car messengers "strongly agree" to this statement. A similar majority also sees E-CBs as a contributor to environmental protection.

Unity between these two groups also holds true for the item with the lowest rate of agreement: only one third of the sample stated that there is sufficient information available on E-CBs and their use. This may be a hint for the possible success of awareness campaigns.

As described above, E-CBs are likely to be positioned between the present markets for bike and car shipments. It is yet to be seen which market will be penetrated more greatly. When asked whether messengers on E-CBs would take over bike or car shipments, we find an almost mirrored perception. Both subgroups tend to see their non-preferred mode of transport challenged by E-CBs.

Finally, about half of the sample either agrees or strongly agrees that E-CBs will be successful in courier logistics services and will have their future place in this business.

\subsection{Possible interactions with job-related features}

Naturally, the type of vehicle used to carry shipments is a profound feature of a messengers' job. Changing to another vehicle might therefore interfere with the persons' job image. It is critical to know what job-related indicators are important for the decision to work as a messenger today and which of these dimensions would change when switching to an E-CB.

Both bike and car messengers found flexibility and having one's own time management a very important aspect about their job (84\%). Otherwise, the 2 groups have different profiles:

- For bike messengers, the possibility of doing exercise while working is of high importance (87\%). Further important aspects are variety from day to day (69\%), contact with people (67\%), ecological footprint of their job (65\%) and direct contact with clients (63\%). They are less interested in the amount of income (importance: $42 \%$ ), their job's image (37\%) or a long-term job perspective (27\%).

- For car messengers, income is a more important aspect (76\%), whereas the jobs' ecological footprint (30\%) and the possibility of doing exercise while working (26\%) are seen as the least important features.

To anticipate possible interactions between mode change and job satisfaction, messengers were asked whether switching from their present vehicle to an E-CB would improve or reduce their satisfaction with jobrelated features. Both user groups see a slight decline in their satisfaction with the most important aspect (flexibility/time management), possibly due to the higher need to plan recharging and parking of the vehicle. Otherwise, again, we see differing assessments of E-CBs:

- Bike messengers expect a more satisfactory income and a slight decrease in the possibility of doing exercise while working. They don't see a deteriorating ecological footprint by using an E-CB.

- Car messengers see a change to E-CB as having a negative effect on their income. Technically, they would see E-CB as a chance to be less disappointed with their job's ecological footprint and to have a 


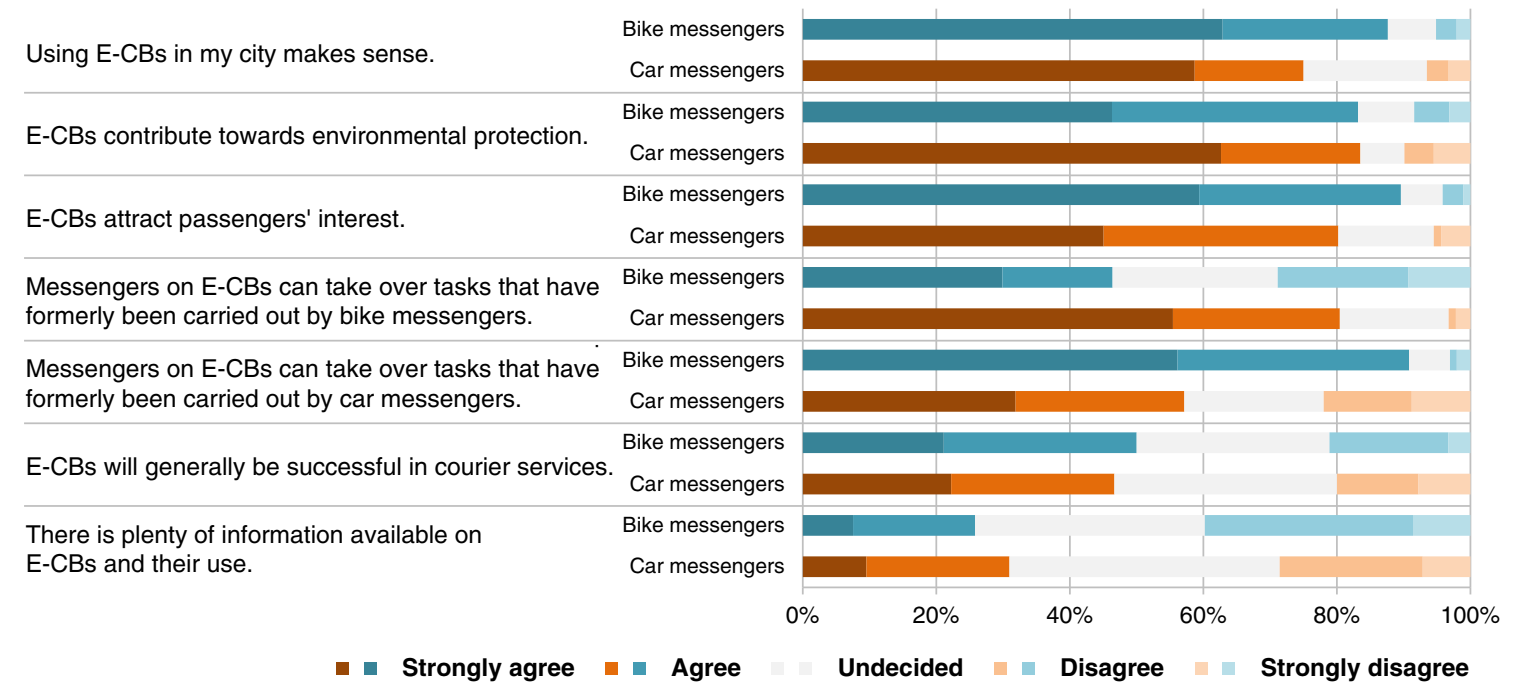

Fig. 6. General assessment of the usability of E-CBs $(n=188)$.

possibility of doing exercise while working. However, as these points have been pointed out as the least important job-related features, and income remains a main job-related feature, it appears highly doubtful that ecological or physical dimensions would motivate car messengers to switch to an E-CB.

\section{Willingness to use an E-CB}

\subsection{Model results}

Would messengers actually change to an E-CB as their preferred vehicle of transportation? 111 of the 191 surveyed messengers (58\%) showed interest in using an E-CB for their job and could therefore be described as willing to use an E-CB. This attitude was not only expressed by bike messengers (72\%), but also by $43 \%$ of the car messengers which demonstrates a general openness of both user groups for this mode of transport.

Next to the differentiating in bike and car messengers, which is customary in the industry, all of the above-mentioned descriptive variables on demographics, job practices and job-related features, and attitudes and values were tested as to whether they contributed to predict messengers' willingness to actually use an E-CB for their services. For the important variables, Table 2 shows the comparison of means by messenger group as well as a binary logistic regression on the willingness-to-use $\mathrm{E}-\mathrm{CB}$ as a dependent variable.

Note that the somewhat arbitrary specifications are the result of extensive trials to derive a theory-consistent model of significant influencing factors while minimizing spurious correlation and multicolinearity.

Table 2

Variables that influence a messengers' willingness to use an E-CB instead of their present vehicle for courier services. Binary logit regression.

\begin{tabular}{|c|c|c|c|c|c|c|c|c|}
\hline & \multicolumn{2}{|l|}{ Means } & \multicolumn{6}{|c|}{ Logistic regression models } \\
\hline & \multirow[t]{2}{*}{ Bike messengers } & \multirow[t]{2}{*}{ Car messengers } & \multicolumn{2}{|l|}{ M1 } & \multicolumn{2}{|l|}{ M2 } & \multicolumn{2}{|l|}{ M3 } \\
\hline & & & Coeff. & $(\mathrm{p})$ & Coeff. & (p) & Coeff. & $(\mathrm{p})$ \\
\hline \multicolumn{9}{|l|}{ Socio-demographics } \\
\hline Age & 35.32 & 48.21 & -0.04 & $(0.00)$ & -0.05 & $(0.01)$ & -0.04 & $(0.04)$ \\
\hline Sex: female & 0.10 & 0.04 & -1.18 & $(0.06)$ & -1.63 & $(0.04)$ & -0.80 & $(0.34)$ \\
\hline Net income: $>€ 2000$ & 0.04 & 0.23 & -0.94 & $(0.06)$ & -1.13 & $(0.05)$ & -1.56 & $(0.02)$ \\
\hline Educational level: low/medium & 0.19 & 0.50 & -0.93 & $(0.01)$ & -1.36 & $(0.00)$ & -1.36 & $(0.00)$ \\
\hline \multicolumn{9}{|l|}{ Professional practices } \\
\hline Car ownership & 0.24 & 0.88 & & & -1.46 & $(0.01)$ & -1.52 & $(0.01)$ \\
\hline Car use for courier service & 0.14 & 1.00 & & & 1.03 & $(0.07)$ & 1.34 & $(0.05)$ \\
\hline Preference for cargo bikes & 0.12 & 0.00 & & & 2.39 & $(0.04)$ & 2.28 & $(0.07)$ \\
\hline Several visits daily at company & 0.41 & 0.28 & & & 0.90 & $(0.04)$ & 0.81 & $(0.08)$ \\
\hline Combining of shipments possible & 0.97 & 0.91 & & & 1.17 & $(0.00)$ & 1.41 & $(0.00)$ \\
\hline Further profit-oriented activity & 0.36 & 0.24 & & & 0.78 & $(0.07)$ & 0.84 & $(0.07)$ \\
\hline Interested in vehicle technology & 0.87 & 0.95 & & & 2.39 & $(0.00)$ & 2.45 & $(0.00)$ \\
\hline \multicolumn{9}{|l|}{ Attitudes and values } \\
\hline "There is plenty of information available on E-CBs." (I strongly agree.) & 0.07 & 0.09 & & & & & 1.74 & $(0.06)$ \\
\hline "E-CBs attract passengers' attention." (I strongly agree.) & 0.58 & 0.45 & & & & & 0.93 & $(0.04)$ \\
\hline "The possibility of doing exercise while working is important." & 0.87 & 0.26 & & & & & 1.21 & $(0.02)$ \\
\hline "The image of my job is not important." & 0.37 & 0.35 & & & & & 1.00 & $(0.03)$ \\
\hline "I am dissatisfied with the ecological footprint of my job." & 0.02 & 0.28 & & & & & 1.37 & $(0.03)$ \\
\hline $\mathrm{N}$ & 99 & 92 & 191 & & 191 & & 191 & \\
\hline Constant & & & 2.75 & $(0.00)$ & 0.04 & $(0.97)$ & -2.27 & $(0.06)$ \\
\hline Pseudo R² (McFadden) & & & 0.12 & & 0.30 & & 0.39 & \\
\hline Log likelihood & & & -114 & & -91 & & -79 & \\
\hline Hit ratio & & & $67 \%$ & & $76 \%$ & & $81 \%$ & \\
\hline
\end{tabular}


We intentionally did not include the messengers' current mode of transport (car vs. bike) into the model for two reasons: First, this information is obviously correlated with other possibly powerful predictors (see comparison of means). Second, when integrating them as additional predictors to the presented specification, they do not contribute to explaining further variance. When comparing the coefficients, one can observe a general tendency of higher willingness-to-use if a predictor lies closer to the bike messengers' mean, but there are important exceptions: Gender, professional car usage, interest in technology and information awareness raise the probability if they lie closer to car messengers' mean values, while shipment combination and job image show a strong positive effect despite their low difference between the two groups' means.

In the first model (M1), only classic socio-demographic variables were considered: age, sex (base: male), income and educational level. All four variables show a negative connection with the messengers' willingness-to-use E-CBs. It decreases significantly with the increasing age of the messenger, in female messengers, in messengers with high income and in those with a low or medium educational level.

In order to achieve higher accuracy, model M2 adds seven variables on job-related background and practices.

Car ownership - independent of whether or not a car is used as a mode of transport for courier services - has a strong negative influence on the dependent variable (willingness to use an E-CB). Messengers that actually use cars for their services regularly seem to be more prepared to use an alternative mode of transport. The minority of messengers that today already prefer (non-electric) cargo bikes show a very high sympathy for E-CBs. A similar degree of sympathy is also expressed by messengers that claimed to be interested in vehicle technology.

Thirty percent of the respondents pursue at least one other profitoriented activity besides their job as a messenger. This group has a more positive attitude towards E-CBs, possibly because of a lower income pressure. We found two more influencing job-related practices: bundling shipments and frequent visits to the site of the courier company.

E-CBs show higher requirements regarding parking and recharging infrastructure than bicycles or (conventional) cars. For the period of the field trial the courier companies provided space on their sites. This fact might be the reason why messengers that already visit the site of their employer at least once a day are more likely to use E-CBs.

Besides socio-demographics and professional practices, the most comprehensive model M3 adds five variables on attitudes and values that have been collected during the messenger survey. M3 delivers the highest hit ratio (81\%) to predict the willingness to use E-CBs. There is a strongly positive association towards E-CB use among respondents that assess existing information on E-CBs as sufficient, raising the importance of awareness campaigns. Several of the above-mentioned job-related indicators also showed significant associations. Messengers who find it important to have the possibility of doing physical exercise during their job stand in favor of $\mathrm{E}-\mathrm{CB}$ use. The same holds true for the subgroup of messengers that do not find the image of their job an issue of importance. Interestingly, drawing attention from people on the street has nonetheless a positive effect on E-CB adoption. Finally, $15 \%$ of the respondents are dissatisfied with the ecological footprint of their job. This attitude is quite strongly associated with the will to switch to an E-CB.

All three models consist of significant coefficients, indicated by the corresponding p-values.

As mentioned above, several further dimensions proved no significant association with the measured willingness-to-use E-CBs, among them, the specific courier company of the respondents, their degree of experience in this job, the preferred type of vehicle parking, and, interestingly, also the annual driven mileage. Thus the assessment of this mode of transport is made in relative independence of one significant cost factor. Indirect influence, however, might be observed in the significant variables of income and further profit-oriented activities.

\subsection{Vehicle assessment}

In a final step we asked all messengers that expressed their interest in using an E-CB for their job to assess the importance of 13 vehiclespecific characteristics. A picture and the technical details of the 2-wheel E-CB pictured in Fig. 1 were given as input. After asking about general importance, these aspects were rated in their anticipated practicability (respondents stated that they had "no doubt" about a specific feature, e.g. speed).

Bike and car messengers show a similar assessment of these items, therefore their joint statements are pictured in Fig. 7.

A prominent exception is electric range, which at the same time is one of the most important features. For car messengers, electric range is more important (79\% vs. $66 \%$ ) than for bike messengers. At the same time, they find the electric range less likely to be suitable for their needs (19\% vs. $37 \%$ ). The electric range can be an advantage for driving comfort. At the same time, however, as batteries are a costly component, the electric range might be a potential obstacle for the acquisition of an E-CB as purchase price is the item that is seen as the most critical. A trade-off between electric range and purchase price can be a barrier to a quick diffusion among messengers.

Car messengers also expressed more doubts about theft protection and payload. More unity between both groups was found for other vehicle-related topics such as convenient handling while driving and general vehicle safety (e.g. stability of frame) or speed. All these aspects are relevant for a purchase decision and rated with a high degree of suitability. E-CBs are largely seen as being environmentally friendly. Charging infrastructure at home or out and about and acceptance

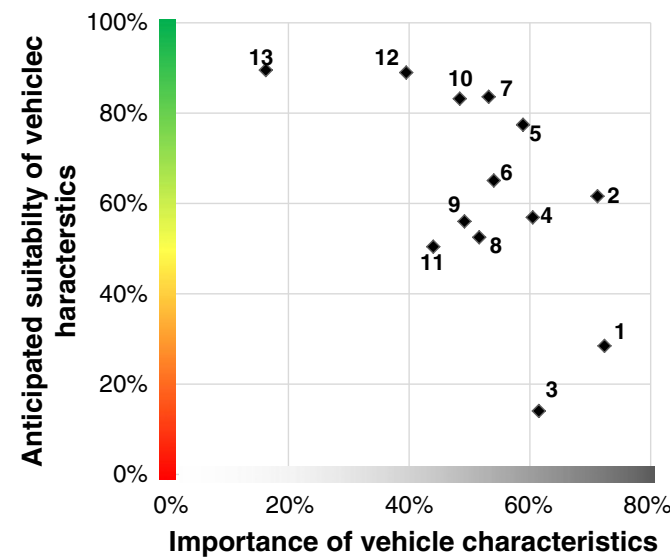

1 Electric range

2 Handling while driving

3 Purchase price

4 Theft protection

5 Vehicle safety

6 Speed

7 Environmental protection

8 Maintenance costs

9 Charging at place of residence

10 Payload

11 Charging out and about

12 Perception/acceptance of customers

13 Perception/acceptance of private surrounding

Fig. 7. Relevant characteristics of E-CBs $(n=127)$. 
by customers and peers are aspects of minor importance and good suitability.

\section{Research implications}

While courier services are a small segment compared to other logistics segments, we find a substantial amount of demand for these high-quality transport services, especially in urban core areas with high economic strength. During daytime bike or car messengers are a common picture on European inner city streets. Car and bike messengers are in direct competition, as their markets largely overlap - spatially, temporally and by type of goods. A car's maximum payload is rarely needed for small-scale deliveries such as media products, documents, spare parts or laboratory samples.

E-CBs are an innovative mode of transport that could be used for courier shipments. As they are positioned between bikes and cars in terms of cost, payload and range, a potential market does exist. It is most likely that E-CBs will have their greatest potential in urban areas, successfully facing problems like congestion and limited access areas due to environmental zones or delivery period restrictions. It is yet to be seen which of the existing markets for bike and car shipments will be penetrated by E-CBs, or even if a new market for this specific vehicle can evolve. Further research might answer in how far E-CB use will be fostered by general trends in the CEP market like the growth of B2C deliveries, micro-consolidation or the demand for high-quality logistics services such as same day delivery.

Regional courier markets are characterized by small and medium companies where structures evolve gradually. Keeping old routines (i.e. for pricing or dispatching) can be barriers for a dissemination of E-CBs. On the other hand, innovators have a possibility to stand out from the logistics mass markets by targeting new costumer groups, implementing cargo bikes in their operational management or even investing in their own E-CB fleet.

Today, vehicle choice is made in a decentralized manner by individual messengers who work as freelance subcontractors for courier companies. Their assessment can be seen as a good proxy for general E-CB-acceptance in this industry. While certain characteristics are highly alike among messengers (predominantly male, technology-oriented, high demand for job flexibility), we detected heterogeneity regarding other dimensions such as age, educational and professional background, working hours, attitudes towards environment and exercise, but certainly also the preferred mode of transport.

The overall positive anticipation of the suitability of E-CBs for courier services differs only little between bike and car messengers. A majority regard this vehicle type as highly competitive for delivery tasks in their specific urban surroundings, which include 7 of the 15 biggest German cities. Furthermore, messengers see E-CBs as an opportunity for generating public attention (and possibly new customers) and contributing towards environmental protection.

Producers of E-CBs should be aware that messengers see a deficit in information. In line with most other current research, electric range and purchase price are seen as the main areas of concern. These doubts of a pioneer user group like messengers could slow down quick E-CB diffusion.

Unlike in other branches of commercial transport where mode choice is the result of highly optimized processes, in courier services different modes compete in a very similar market and personal dimensions such as socio-demographic background or lifestyle influence the decision for a certain vehicle.

If $\mathrm{E}-\mathrm{CBs}$ are to make a contribution to a more-sustainable urban transport, future research will have to show which conditions, incentives or regulations are needed to motivate their use by operators and drivers.

\section{References}

Ben-Akiva, M., \& Lerman, S. R. (1985). Discrete choice analysis: Theory and application to travel demand. Cambridge, MA: MIT Press.

BIEK (Bundesverband Internationaler Express-und Kurierdienste) e.V. (2013). Motor für Wirtschaftswachstum und Beschäftigung - Die Kurier-, Express- und Paketbranche in Deutschland. http://biek.de/index.php/dokumente.html?file=tl_files/biek/downloads/ papiere/BIEK\%20KEP\%20Studie\%202013\%20klein.pdf (accessed September 19, 2013)

Browne, M., Piotrowska, M., Woodburn, A. G., \& Allen, J. (2007). Literature review WM9: Part I - Urban freight transport, carried out as part of work module 1, Green Logistics project. Green Logistics Report. University of Westminster.

Cheng, Y., \& Yeh, Y. (2011). Exploring radio frequency identification technology's application in international distribution centers and adoption rate forecasting. Technological Forecasting and Social Change, 78(4), 661-673.

Conway, A., Fatisson, P., Eickemeyer, P., Cheng, J., \& Peters, D. (2011). Urban micro-consolidation and last mile goods delivery by freight-tricycle in Manhattan: Opportunities and challenges. Conference proceedings, Transportation Research Board 91st Annual Meeting 2012.

Dablanc, L. (2011). Transferability of urban logistics concepts and practices from a worldwide perspective - Deliverable 3.1 - Urban logistics practices - Paris case study. TURNBLOW_WW Project. http://89.152.245.33/DotNetNuke/Portals/Turblog/ DocumentosPublicos/CaseStudies/TURBLOG_D3.1ParisFV.pdf (accessed: August 2, 2013)

Destatis (2013). Bevölkerung nach allgemeinen und beruflichen Bildungsabschlüssen 2012. https://www.destatis.de/DE/ZahlenFakten/GesellschaftStaat/BildungForschungKultur/ Bildungsstand/Aktuell.html (accessed September 20, 2013)

Giuliano, G., O'Brien, T., Dablanc, L., \& Holliday, K. (2013). NCFRP Project 36(05) synthesis of freight research in urban transportation planning. Washington D.C.: National Cooperative Freight Research Program.

Glaser, J. (2000). Kurier-, Express-, Paketdienste und Stadtlogistik. Analysen und konzeptionelle Ansätze zur Gestaltung des städtischen Güterverkehrs am Beispiel der Kurier-, Express- und Paketdienste (KEP-Dienste) in Hamburg. (Munich).

Holguín-Veras, J., \& Wang, Q. (2011). Behavioral investigation on the factors that determine adoption of an electronic toll collection system: Freight carriers. Transportation research part C: Emerging technologies, 19(4), 593-605.

Infas geodaten $\mathrm{GmbH}$ (2011). Corporate location data base. (Datenstand 12/2011).

Jongeneel, R. A., Polman, N.B. P., \& Slangen, L. H. G. (2008). Why are Dutch farmers going multifunctional? Land Use Policy, 25(1), 81-94.

Le Galès, P., \& Zagrodzki, M. (2006). Cities are back in town: The US/Europe comparison. Cahier Européen numéro 05/06 du Pôle Ville/métropolis/cosmopolis. Paris: Centre d'Etudes Européennes de Sciences Po.

Lenz, B., \& Riehle, E. (2012). Bikes for Urban freight? - Experience for the European case Conference proceedings, Transportation Research Board 92th Annual Meeting 2013.

Leonardi, J., Browne, M., \& Allen, J. (2012). Before-after assessment of a logistics trial with clean urban freight vehicles: A case study in London. Procedia - Social and behavioral sciences, 39. (pp. 146-157).

Liu, W., Wang, C., \& Mol, A. P. J. (2013). Rural public acceptance of renewable energy deployment: The case of Shandong in China. Applied Energy, 102, 1187-1196.

Maes, J., \& Vaneslander, T. (2012). The use of bicycle messengers in the logistics chain, concepts further revised. Procedia - social and behavioral sciences, 39. (pp. 409-423).

Mariano, M. J., Villano, R., \& Fleming, E. (2012). Factors influencing farmers' adoption of modern rice technologies and good management practices in the Philippines. Agricultural Systems, 110, 41-53.

MRU GmbH (2012). Der KEP-Markt in Deutschland. Hamburg. http://bdkep.de/ dokumente/studie/2012kurzstudie.pdf (accessed September 20, 2013)

Riehle, E. (2012). Das Lastenfahrrad als Transportmittel für städtischen Wirtschaftsverkehr. Eine Untersuchung europäischer Beispiele zur Abschätzung von Rahmenbedingungen und Potenzialen für deutsche Städte. Dortmund: Transport Systems and Planning, Technical University Master's thesis in the subject area.

Schumacher, P. (2012). Deutsche Post DHL. Pro Tag 15000 Pakete und Päckchen. Bonner Rundschau. http://www.rundschau-online.de/bonn/deutsche-post-dhl-pro-tag-15 000-pakete-und-paeckchen,15185502,21153024.html (accessed February 27, 2014)

Cycle freight in London: A scoping study. Transport for London (Ed.). (2009). London: Mayor of London (http://www.tfl.gov.uk/assets/downloads/businessandpartners/ cycle-as-freight-may-2009.pdf, accessed: August 23, 2013).

van Duin, J. H. R., Tavasszy, L. A., \& Quak, H. J. (2013). Towards E(lectric)-urban freight: First promising steps in the electric vehicle revolution. European Transport/Trasporti Europei, 54(9).

Witte, C., Krichel, P., \& Sommer, C. (2011). Verlagerung des Lieferverkehrs auf Fahrradkuriere - Methode und Ergebnisse einer Potenzialstudie. Clausen, $U$. Wirtschaftsverkehr 2011 Modelle - Strategien - Nachhaltigkeit (pp. 158-170) (Dortmund)

Ye, L., Mokhtarian, P. L., \& Circella, G. (2012). Commuter impacts and behavior changes during a temporary freeway closure: The 'Fix I-5' project in Sacramento, California. Transportation Planning and Technology, 35(3), 341-371. 